Please cite as:

Dolnicar, S. (2020) Designing for more environmentally friendly tourism. Annals of Tourism Research, 84:102933.

https://doi.org/10.1016/j.annals.2020.102933

\title{
Designing for more environmentally friendly tourism
}

\author{
Sara Dolnicar, The University of Queensland, Australia
}

\author{
A RTICLE INFO
}

Keywords:

Environmental sustainability, design, experiment, choice architecture, nudging, social norm

\author{
A B S T R A C T
}

The environmental (un)sustainability of the tourism industry has been debated for many decades. This debate generated ample empirical evidence of the environmental damage caused by tourism-related human activity. It is underpinned, however, by a passive position: one of largely accepting the tourism industry as it is, and lamenting its negative consequences. An alternative, more active approach, is to deliberately design for environmental sustainability. This article provides examples of how the tourism industry can drive a reduction of environmental damage by actively designing brand-owned touchpoints in a way that entice tourists to behave more environmentally friendly. The article concludes with an overview of promising design approaches and a framework to guide the future design of more environmentally friendly tourism services.

\section{Introduction}

Going on vacation is not environmentally friendly. As tourists, we harm the environment in many different ways. We cause carbon emissions by traveling to the holiday destination of our dreams. We stay at fancy hotels with pools, which need to be refilled with water and maintained with chemicals on an ongoing basis. We enjoy nice, long, hot showers. We set the room thermostat to the exact temperature we want, and run it all the time, sometimes with the windows open to enjoy a boost of fresh air. We indulge in our bright white, soft and fluffy fresh towels every day. We taste-test as many food items as humanly possible at the breakfast buffet, but only finish what we like, sending the rest to landfill to produce methane. As tourists, we do not behave in the same environmentally responsible way as we do at home (Dolnicar \& Grün, 2009). We forgive ourselves for being a little bit naughty. And if we find ourselves feeling guilty about it, we quickly construct an explanation so our guilt does not overshadow our holiday enjoyment (Buckley, 2011; Juvan \& Dolnicar, 2014). 
Not surprisingly, therefore, tourism is among the most polluting industries globally. It generates eight percent of all global greenhouse emissions (Lenzen et al., 2018). Its contribution to global warming is estimated to be as high as $12.5 \%$ (United Nations Environment Programme and World Tourism Organization, 2012). More tangibly: the tourism industry creates some 35 million tons of waste every single year (United Nations Environment Programme and World Tourism Organization, 2012), and is exceptionally water-hungry at an average 300 litres of water used to provide accommodation for one single tourist for one night (United Nations Environment Programme and World Tourism Organization, 2012). An improvement is not in sight.

Technological development is unlikely to bring a step change in the reduction of resource use or waste generation (Midden, Kaiser \& McCalley, 2007). And the number of tourists travelling each year continues to increase, with annual growth predictions for the tourism industry at about five percent (United Nations Tourism World Organisation, 2016).

The environmental harm caused by tourism has been documented for many decades. In the inaugural editorial of the Journal of Sustainable Tourism, the editors trace the beginnings of the academic discussion of environmentally sustainable tourism to Krippendorf, Zimmer and Glauber (1988) and note that "Good intentions and idealism alone are not a sufficient basis for real advances" and that "All those involved in tourism have a responsibility to learn how to contribute towards more sustainable forms of tourism" (Bramwell \& Lane, 1993, p. 3). Bramwell and Lane - in 1993, when international tourism arrivals were at only 405 million per annum - highlighted the urgent need to design for more environmentally friendly tourism. Nearly 30 years later - with billions of people travelling each year - we are still in desperate need of practical approaches to achieve this challenging and ambitious aim.

The present paper responds to Bramwell and Lane's call for designing environmentally sustainable tourism. It focuses in scope on targeting environmentally significant behaviours of tourists - as opposed to the behaviour of policy makers or staff working in the tourism industry. To be environmentally significant, a behaviour must have an impact on the environment, it "changes the availability of materials or energy from the environment or alters the structure and dynamics of ecosystems or the biosphere itself" (Stern, 2000, p. 408). Throughout this article, the term environmentally friendly behaviour is understood to mean positive environmentally significant behaviour, behaviour which leads to positive effects on the environment or reduces negative effects.

The article is structured as follows: first, approaches proven to reduce environmental harm caused by tourists at the destination are discussed in detail. Many of these approaches can be implemented in a way that represents a win-win situation: they have the potential to reduce both the environment damage and business operating cost. Reduced operating cost increases the likelihood of uptake by the tourism industry. After the detailed discussion of existing design approaches, a conceptual model of promising design approaches is proposed. Finally, a methodological framework is offered to guide researchers and tourism industry in the development of new designs that will reduce the environmental footprint of the tourism industry in future.

This article provides the tourism industry with immediate guidance on how to reduce the environmental damage caused by their operations by highlighting interventions which have proven successful in experimental studies, and putting forward an approach industry can use to develop their own new interventions. From an academic perspective, this article aims at instigating a change in direction of research in the field of environmentally sustainable tourism 
away from problem description and towards the development and empirical testing of practical solutions. Increased environmental sustainability does not result from alerting the world to the problem. Rather, it results from proactively implementing practical measures that are scientifically proven to be effective. In so doing, step by step, we can help the tourism industry "develop in such a way that productivity can be sustained over the long term for future generations" while "preserving essential ecological processes" and protecting biodiversity (Bramwell \& Lane, 1993, p. 2).

\section{Theories of human behaviour}

Changing human behaviour is an ongoing challenge in the social sciences. Many theories have been put forward to explain different kinds of human behaviour and, based on this understanding, change it. The vast majority of these theories could, in one way or another, inform the development of interventions aiming at making tourists behave in more environmentally friendly ways. Covering such a broad range of theories is not possible in this article, but we illustrate how theories of human behaviour can be leveraged using a few examples. Some of these theories have already been used as the basis of successful interventions. These are discussed in the next chapter.

Attribution theory (Heider, 1958), for example, states that people explain consequences of their behaviour in one of two ways: internally by viewing themselves as the cause of the consequence, and externally by viewing other factors as the cause. Attribution theory suggest that it may be possible to alter people's attribution from external to internal and, in so doing, reduce behaviour that leads to environmentally negative outcomes.

Another example of a potentially useful specific theory of human behaviour is cognitive dissonance theory (Festinger, 1957): people have an intrinsic desire for their behaviours to align with their beliefs. If they perceive themselves as environmentally friendly, they want to behave in environmentally friendly ways. When their behaviour causes environmental harm, they perceive a tension - cognitive dissonance. They can reduce this tension in two ways: change their behaviour or change their beliefs. Cognitive dissonance theory can be leveraged by developing communications that make it more difficult for tourists to change their beliefs, increasing the likelihood of consonance being re-established through behavioural change. A special case of Festinger's cognitive dissonance theory is equity theory (Adams, 1963). It postulates that people seek a balance in social exchanges; they feel tension if they give much more or much less than they receive from the same exchange partner. They adjust their giving to establish equity of giving and receiving. This theory could also be leveraged in an attempt to change tourist behaviour by proposing an exchange benefitting both tourism businesses and tourists, while simultaneously reducing environmental harm.

Social identity theory (Tajfel, 1979) explains human behaviour in groups, in social contexts, by understanding the part of a person's self-concept that is determined by the social group they are member of. Positive behaviours can result from trying to achieve a positive social identity. The norms in the reference group are critically important in determining the nature of that behaviour. In the sustainable tourism context, social identity theory can be leveraged by making people aware of the expectations of the relevant reference group. 
Many other psychological theories propose mechanisms that could inform the design of interventions aimed at making tourists behave in more environmentally sustainable ways. These theories are not specific to a particular behavioural context. The only theory that has been developed specifically in view of understanding and changing pro-environmental behaviours is that of Stern and colleagues $(1999,2000)$. Their theory - based on norm activation theory (Schwartz, 1977) - aims at explaining environmentally significant behaviour. The key leverage points are two specific beliefs, one relating to harm done by a certain behaviour to an object of value, and the second one relating to the belief that changing the behaviour can reduce that harm.

A less well-known framework, which is particularly pertinent in the tourism context is that of happiness economics or hedonic psychology (Kahneman, 1999). Kahneman argues that peopleat any moment in time - experience good, bad, or neutral instant utility. They want to engage in behaviours which have high instant utility - making them happy. Hedonic psychology offers an excellent starting point for designing interventions aiming at behavioural change in tourism because engaging in tourism activities is inherently pleasure-seeking. Offering a further increase in instant utility, therefore, is likely to be very powerful.

Another approach that has received substantial attention among public policy makers over the past decade is changing choice architecture (Sunstein \& Thaler, 2008). Most human behaviours involve a choice among alternative behaviours. Changing how these choices are presented is a powerful way of influencing human behaviour. Importantly, people are still free to behave in whichever way they want, but the presentation of choice alternatives nudges - not forces - them towards displaying the desired behaviour.

Synthesising work on theories of human behaviour reveals - despite the use of different terminology - a substantial amount of consensus about the kind of interventions that have the potential to change behaviour. Such interventions fall into four areas: leveraging people's beliefs, leveraging people's social norms, increasing pleasure or instant utility, and altering choice architecture. The remainder of this article follows this structure, using these four categories to guide the discussion of the effectiveness of interventions developed in the past, and to offer a conceptual model of designing for environmentally sustainable tourism.

\section{Designing tourism experiences to be more environmentally friendly}

\section{Leveraging beliefs}

Beliefs are generally viewed as critically important to changing behaviour. Advertising, for example, attempts to modify consumer beliefs to increase purchase likelihood. But in the context of making people in pleasure-focused contexts behave more environmentally friendly, beliefs have not emerged as a particularly successful approach. This is despite the fact that some theories that have been specifically developed to explain environmentally significant behaviour (Stern, 2000) view beliefs as integral in explaining why people behave in environmentally friendly ways.

A few studies tested the effectiveness of pro-environmental appeals. These appeals aimed at activating or modifying beliefs known to be antecedents to the desired behaviour. The effect of the pro-environmental appeal was consistently negligible: when sharing the savings of a waived daily room clean with guests, for example, the additional pro-environmental appeal at hotel 
guests' beliefs had no effect above and beyond the effect of sharing the savings (Dolnicar, Kneževič Cvelbar \& Grün, 2019a). A study dedicated specifically to testing the effect of activating beliefs to reduce water use, and increase towel reuse also failed to show any effect of this measure (Dolnicar, Kneževič Cvelbar \& Grün, 2017). These empirical findings are not altogether surprising given that informational strategies are expected to be effective in cases where the desired environmentally friendly behaviour is convenient, does not take much time or effort and occurs in a context free of constraints (Steg \& Vlek, 2009). These conditions are not met when tourists go on holiday away from home in pursuit of pleasure.

\section{Leveraging social norms}

Most theories of human behaviour acknowledge that people are influenced by other people around them, especially people whose opinion they value. Social influence stands at the centre of social identity theory. In the theory of planned behaviour (Ajzen, 1985) it is referred to as social norm. Social norms have emerged as a promising design approach. Social norms refer to a collective understanding of behavioural expectations by society.

Social norms can successfully be managed in a number of different ways, some of which have been proven in quasi-experimental field studies to significantly improve environmentally friendly behaviours among tourists. Towel reuse, for example, can be increased by informing hotel guests how many other hotel guests have reused their towels. Results from a field study conducted in a mid-range hotel in the USA observing towel reuse on 1058 occasions show that this approach leads to a higher towel reuse rate (44\%) than the signs typically used in hotels which ask guests to help the hotel with environmental protection (35\%; Goldstein, Cialdini \& Griskevicius, 2008). In a quasi-experimental follow-up study using further refined messages in the same hotel, the observation of 1595 possible towel reuse occasions led to additional insights: adding information about the types of guests who reused towels does not further increase reuse. But stating the room-specific towel reuse rate pushes towel reuse to $49 \%$. A study in four Australian motels provides additional empirical evidence for these findings: leveraging social norms, in this study, increased towel reuse from an already high baseline of $84 \%$ to $88 \%$. A similarly good result was achieved by explicitly requesting help by guests (Mair \& Bergin-Seers, 2010). In the same study, a compensation for reusing towels was unsuccessful. The compensation was not to the guest directly, but rather a donation to a charity.

The power of direct compensation for more environmentally sustainable behaviour as a tourist is demonstrated by Dolnicar, Kneževič Cvelbar and Grün (2019a). Resembling the design in Mair and Bergin-Seers (2010), this study had two experimental conditions and used voluntary opting out of daily routine hotel room cleaning as target behaviour. The aim was to reduce routine room cleaning without reducing guest satisfaction. In one of the experimental conditions, guests were provided with environmental facts about the negative impact of room cleaning, and asked to reduce this impact by voluntarily opting out of room cleaning. To opt out, guests had to hang a sign on the outside handle of their hotel room door indicating that they requested for the room not to be cleaned. In the second experimental condition, guests were informed that room cleaning is very expensive. Not cleaning hotel rooms unnecessarily, therefore, saves the hotel a lot of money. Guests were then told that the hotel was happy to share those savings with them: for every day a guests waived the room clean, they received free drinks vouchers for each adult in the room. The third experimental condition combined the drinks voucher and the pro- 
environmental appeal. The study ran for three weeks, and analysis was based on 678 nights by 324 guest parties who stayed for more than one night. The equity-theory (Adams, 1963; Adams \& Freedman, 1976) based condition where savings were shared with the hotel guest - as opposed to being donated to a charity - reduced hotel cleans by $42 \%$. Adding the pro-environmental appeal did not further significantly reduce opting out of room cleaning. Importantly, the industry standard - providing environmental facts and asking the guest for help - performed worst.

Another instance of leveraging the perceived give and take between hotel guest and tourism businesses, while at the same time proactively trying to increase the holiday enjoyment of a specific group of tourists, is to offer stamp collection booklets and rewards for families. Specifically, families staying at a seaside resort were invited to play a stamp collection game. Every time the entire family did not generate any plate waste at dinner, they received a stamp from the waiter. If they collected one stamp for each day of their stay, they received a small prize at check-out. This initiative reduced plate waste among families by $34 \%$ (Dolnicar, Juvan \& Grün, 2020). Both studies (drinks vouchers and stamp collection booklets) have another thing in common, which is not related to social norms: they increase the pleasure of tourists, they enhance the consumer experience at brand-owned and social touchpoints (Lemon \& Verhoef, 2016). Hotel guests enjoyed their free drinks, and children enjoyed collecting stamps and were very excited to be rewarded for their efforts with a prize at check-out. Both studies, therefore, are examples of interventions which genuinely represent win-win-win situations: environmental harm is reduced, guest satisfaction is increased, and hotel costs decrease.

Social norms can be taken one step further by getting tourists to commit to displaying a socially desirable behaviour and providing an avenue that allows them to communicate their socially compliant behaviour with the community. This is exactly the design approach taken by Baca-Motes, Brown, Gneezy, Keenan and Nelson (2012). In this field study, receptionists informed guests at check-in that the hotel is taking action to minimize harm to the environment, and invited guest to voluntarily commit to making a contribution to this initiative. The commitment was either general in nature, or specifically relating to towel reuse. Some guests who chose to make the commitment also received a pin that they could wear. The pin signalled their towel reuse commitment to other guests and staff in the hotel. The interventions tested in this study were developed using as theoretical basis cognitive dissonance theory (Festinger, 1962), signalling theory (e.g. Andreoni \& Bernheim, 2009), and prior empirical findings that higher specificity of requests leads to higher levels of agreement to commit (Locke \& Latham, 2002). The most effective intervention was the specific commitment to reusing towels combined with wearing the pin. Guests who were in this experimental condition had a towel reuse rate of $35 \%$, compared to a base rate of $24 \%$. These results illustrate the effectiveness of leveraging social norms through signalling. If the hotel in which the study was conducted would adopt the intervention of inviting guests to commit to towel and giving them a pin to publicly signal their commitment, it would save the hotel washing some 150,000 towels annually. Not only does this imply a substantial cost saving, estimated at some $\$ 50,000$ per year, it also saves water, electricity and the detergent used for washing and softening the towels. Guest satisfaction was not negatively affected.

Yet another approach to managing social norms to design for environmentally sustainable tourism has proven successful in the context of minimizing plate waste at hotel buffets (Kallbekken \& Sælen, 2013): a table sign inviting guests to return to the buffet as often as they wish and explain that this is better than taking too much at once and then not being able to eat it 
all reduced plate waste by $21 \%$. The social norm perceived by guests in this instance is that it is not acceptable to go back to the buffet too many times. To avoid being seen as greedy, hotel guests take more food in one trip, increasing the likelihood of serving themselves more than they are able to eat. The table sign modified the social norm; it tells guests that it is acceptable to go back to the buffet many times. More even: it is desirable to display this behaviour. This intervention also reduces hotel cost without negatively affecting guest satisfaction.

\section{Increasing pleasure}

Increasing the holiday enjoyment of tourists - their instant utility - in an attempt to make them behave in more environmentally friendly ways is an uncommon approach. Most measures taken by tourism businesses rely on using signage to activate pro-environmental beliefs, or induce guilt in an attempt to trigger pro-environmental behaviour. Only a small number of studies have successfully - tested this approach to date. Dolnicar, Juvan and Grün (2020) reduced plate waste generated by families at the hotel buffet breakfast by $34 \%$ by introducing a stamp collection game for children, which demonstrably increased these children's holiday enjoyment as they were working towards receiving a prize at the end of their stay. Similarly, daily routine room cleaning rates in hotels were reduced by $42 \%$ (Dolnicar, Knezevic Cvelbar \& Grün, 2019) by giving hotel guests a drinks voucher for every day they voluntarily waived room cleaning. This intervention was designed to leverage equity theory, yet the increased pleasure derived from a free drink was an obvious side-effect of the hotel reciprocating guests' waiving of room cleans. Although linking the desired behaviour to increased pleasure is an uncommon approach, it shows substantial promise in pleasure-seeking behaviour contexts, as it aligns directly with Kahneman's (1999) theoretical predictions that people will engage in behaviours which have high instant utility, which make them happy. This approach is also the most desirable in terms of reducing environmental harm, saving the business operating costs and increasing holiday fun (as opposed to not reducing it).

\section{Designing choice architecture}

Modifying choice architecture has proven successful across a range of applications. In the context of private health insurance, for example, presenting health covers to consumers in order from best to worst, as well as breaking up one large choice task with many options into many smaller choice tasks with fewer options, significantly improves the outcome for consumers (Dellaert, Johnson \& Baker, 2019). In some instances, the choice architect can influence a range of dimensions of the choice architecture, including the structure of the choice task, and the description of choice options (Johnson et al., 2012). In terms of choice structure, a choice architect can vary the number of alternatives and decision tools available to consumers, redirect consumer attention to attractive options which occur later in time, break up complex choices in a larger number of less complex choices, and set default options to increase the likelihood of the desired behaviour occurring because consumers do not put in the effort to pursue an alternative behavioural option (Johnson et al., 2012).

In tourism, an example of altering choice architecture to improve environmental outcomes is the use of video content to elicit specific emotions just before a travel package is being booked (Araña \& León, 2016). In this experimental study, senior travellers who were choosing a holiday package were presented - before they chose one of many available packages - with no video, a 
video triggering sad emotions, or a video triggering empathy for future generations. Both videos triggering emotions led to travel packages with lower $\mathrm{CO}_{2}$ emissions being chosen, with the empathy condition proving most powerful. This intervention can be implemented easily and at low cost in any online booking interface.

The most prominent example of a small change in physical infrastructure that caused a major change in guest behaviour is the reduction of the size of plates made available to hotel guests at the breakfast buffet (Kallbekken \& Sælen, 2013). The field experiment was conducted in 52 hotels that are part of the same hotel chain, and used food waste generated by each hotel as the dependent variable. Of the 52 hotel, 38 served as control condition. In those hotels food waste was measured, but infrastructure was not altered. In seven hotels the size of the plates available to guests at the buffet was reduced by three centimetres (from $24 \mathrm{~cm}$ to $21 \mathrm{~cm}$ ). As a consequence, the food waste generated in the hotel dropped significantly, by $19.5 \%$. The results from this field study are further supported by an observational study, which used the food waste generated by all the groups in the control condition to test for associations with the plate sizes they offered in each of the hotels. Specifically, one centimetre smaller plates were associated with $2.5 \mathrm{~kg}$ less food waste per day (or $7.4 \%$ ), aligning almost perfectly with the reduction in waste of approximately $20 \%$ derived from the field experiment.

Importantly, this design approach to making hotel operations more environmentally sustainable does not cause additional expenses to hotels. Rather, it reduces operating costs in two ways. Firstly, smaller plates are cheaper. Given that hotels have to purchase new plates on an regular basis, this difference in purchase cost is significant over the years. The second source of savings is the actual reduction in food waste. Food waste is expensive for a hotel because the food need to be purchased and prepared. If it is not eaten, disposal has to be paid for. Reducing food waste is estimated to save the hotel some nine dollars per kilogram (Kallbekken \& Sælen, 2013) and reduce the burden on the environment by $1.9 \mathrm{~kg}$ of $\mathrm{CO}_{2} \mathrm{e}$ (Kallbekken \& Sælen, 2013). This infrastructure intervention represents a design option that creates a genuine win-win situation. It also has no measurable effect on guest satisfaction: hotel guests' rating of their satisfaction with the hotel buffet breakfast are the same for the hotels in the control group and the hotels in the experimental group.

The potential environmental benefits of such a small design change are material indeed: billions of tourists go on vacation every year and, typically, stay more than one night. Each morning at breakfast they leave, on average, 15 grams of food they had taken from the buffet on the plate uneaten upon completion of their meal (Juvan, Grün \& Dolnicar, 2018). Globally, the environmental footprint of leaving food uneaten is substantial (250 cubic kilometres of water and $3.3 \mathrm{Gt}$ of $\mathrm{CO}_{2}$ equivalent, Food and Agriculture Organization of the United Nations, 2013), placing global food waste right behind the USA and China in terms of carbon emissions (Food and Agriculture Organization of the United Nations, 2013).

In the context of hot water used by tourists in hotel showers, providing instant feedback to the tourists on how many litres they are using while showering leads to tourists shortening their showers (Tiefenbeck et al., 2019). In this study - based on nearly 20,000 instances of real tourists taking a shower in one of 265 hotel rooms - energy use was reduced by $11 \%$. This is despite that fact that they did not receive any kind of discount or acknowledgement for their energy saving efforts. 
Another approach that falls into the category of choice architecture is changing defaults. Defaults are behavioural options that require "no action with regard to particular choice opportunity" (Davidai, Gilovich \& Ross, 2012, 15201). Public policy makers are well aware of the power of defaults, and use them proactively to alter people's behaviour in areas other than tourism. The classic example is organ donation. When people need to take action to consent to their organs being donated, the donation rate is only around ten percent. When consent is assumed by the government, but people have the option to take action to withdraw consent, the donation rate is close to $100 \%$ (Johnson \& Goldstein, 2003).

The power of changing defaults can be harvested in many different ways in tourism. In the context of conference and convention travel, Araña and León (2013) prove how changing the default invitation to offset carbon emissions voluntarily affects the offsetting rate. In this field experiment, 856 conference or convention travellers were given the option to tick a box to add the carbon offset cost to their total conference package price. Another 824 travellers were given the option to tick a box to deduct the offset amount - which was included in the price by default - from the conference package. Travelers were more likely to offset carbon emissions when they had to opt out then when they had to opt in, although the strength of the change in defaults was dependent on the cost of the offset. The higher the cost, the lower the gap between opting in and opting out. When converted into willingness to pay, conference travellers who had to opt out were willing to pay 40 Euros for their offset. Those offered the opportunity to opt in were only willing to pay 26 Euros.

A second illustration of the power of defaults in tourism has been provided in a study attempting to reduce the number of routine daily room cleans in a three-star hotel in Slovenia (Kneževič Cvelbar, Grün \& Dolnicar, 2020). In this quasi-experimental field study, guests arriving in the hotel during the European summer months were exposed to two basic conditions: (1) the room was cleaned daily, unless the guest requested for it not to be cleaned (opt-out condition), and (2) the room was not cleaned daily, unless the guest requested it be cleaned (optin condition). A second opt-in condition, which contained an environmental justification for the change in default, was also tested. This study is quasi experimental because it was conducted with real hotel guests. As a consequence, subjects (hotel guests) could not be randomly assigned to one of the three experimental conditions. Overall, 989 overnight stays were included in the analysis. The opt-out condition reduced room cleans by $63 \%$. The pro-environmental appeal did not lead to a significant improvement above and beyond the basic opt-in condition. The environmental benefits of this design approach are substantial: one room clean consumes approximately 35 litres of water, $100 \mathrm{ml}$ of chemicals, and $1.5 \mathrm{kWh}$ of electricity (Dolnicar, Kneževič Cvelbar \& Grün, 2019a). Multiplied by billions of tourists travelling internationally and domestically every year, the reduction in resource use from implementing such a design approach would indeed be substantial. In addition, the hotel would benefit financially by saving the money associated with paying for the use of these resources, as well as the labour associated with each room clean.

Replacing thick cotton serviettes with recycled paper serviettes at breakfast buffets is another example of where changing the default can make a difference. While, strictly speaking, this field study based on data from 10,970 overnight stays during the European summer season did not offer the exact symmetric option for the opt-in and the opt-out conditions, replacing cotton serviettes with recycled paper serviettes on the breakfast tables (while still allowing guests to get a cotton serviette from the buffet station, and informing them about the reason for providing 
recycled paper serviettes) reduced the use of cotton serviettes by 95\% (Dolnicar, Kneževič Cvelbar \& Grün, 2019b). Guests were aware of the change, but the provision of recycled paper serviettes did not reduce stated satisfaction with the breakfast service. In the months of July and August alone, this change in default would save 265 kilograms of $\mathrm{CO}_{2}$ emissions in the hotel in which the study was conducted. In addition, the provision of recycled paper serviettes is cheaper for the hotel than replenishing the stock of cotton serviettes regularly, and washing and ironing each serviette between uses.

Figure 1 summarizes the insights gained to date from studies that have developed theory-based interventions and tested them in the field using experimental or quasi-experimental research designs (discussed in detail in the previous section). On the far right hand side is the desired outcome: making tourists behave more environmentally friendly at the destination. The arrows indicate a range of approaches which have been tested to date. The length of the arrow indicates the effectiveness with longer arrows proven to be more effective.

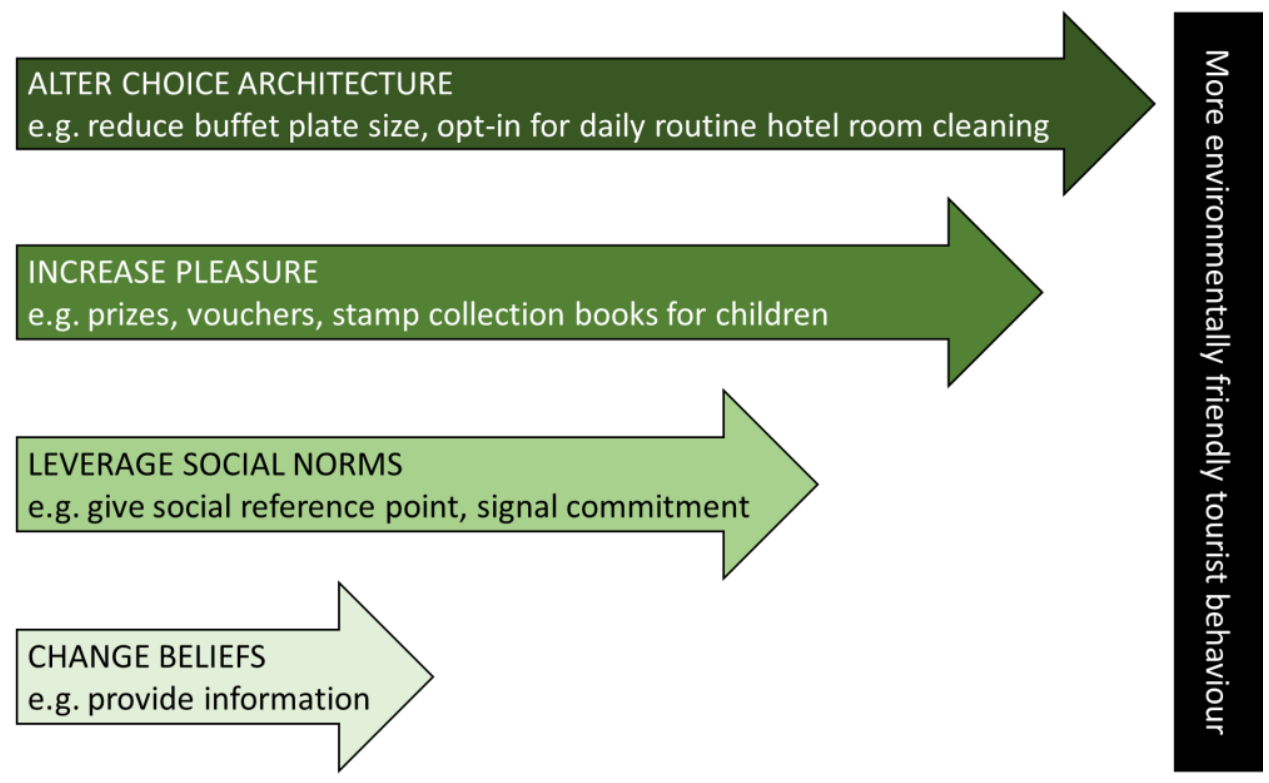

Fig. 1. Approaches to designing for more environmentally friendly tourist behaviour.

Default changes have proven particularly effective outside the field of tourism (e.g. Abadie \& Gay, 2006; Everett, Caviola, Kahane, Savulescu \& Faber, 2015; Johnson \& Goldstein, 2004; Johnson, Hershey, Meszaros \& Kunreuther, 1993; Leonard 2008; Samuelson \& Zeckhauser, 1988). The small number of studies on defaults in tourism confirms these findings, making defaults one of the more promising approaches to designing more environmentally sustainable tourism. There is ample opportunity to consider changing defaults in tourism: countries, destinations or tourism businesses could make environmentally sustainable options the norm.

If defaults cannot be changed, changing infrastructure is the second most powerful choice architectural design option to consider. While infrastructure changes cannot be made to the extent where they affect the holiday enjoyment of tourists, there is still substantial potential in today's tourism industry to make small infrastructure modifications - such as offering smaller plates at buffets - that do not reduce vacation enjoyment, but lead to tourists behaving more environmentally friendly. 
The most promising of the less invasive approaches is to increase holiday enjoyment for those tourists who display the desired behaviour. Holidays are inherently pleasure-focused. The primary aim of any tourists is to maximize pleasure. This desire stands in direct opposition to containing oneself to protect the environment. If, however, the desired behaviour leads to additional pleasure (good instant utility, Kahnemann, 1999), the likelihood of tourists engaging in such behaviour is substantially increased. Pleasure can be increased through refunds, rewards, prizes, gifts, access to special spaces, services and offers.

Social norms have proven to work well in changing people's behaviour, including tourists' environmentally significant behaviour. The effect sizes, however, are substantially lower than those that can be achieved with changing the default, changing infrastructure or increasing pleasure. Attempts of activating or changing beliefs, arguable the current industry standard, is the least promising approach to designing tourism to be more environmentally friendly. This is because of the unique hedonic context of the vacation experience, and the fact that proenvironmental behaviour is harder to display in an environment controlled by someone else. Note, however, that the summary in Figure 1 is based only to interventions that have already been developed and experimentally tested. New, creative ways of modifying beliefs could prove effective in future.

\section{A framework for designing tourism services to be more environmentally sustainable}

All studies discussed in this article share the same underlying approach. This approach forms the basis of the general framework for design to improve the environmental sustainability of the tourism industry illustrated in Figure 2, which is similar to the approach proposed by Steg and Vlek (2009). The starting point is the analysis of behaviours displayed by tourists in view of the negative environmental impacts they cause. These behaviours could occur in the pre-purchase, the purchase, or the post-purchase phase (Dhebar, 2013), but they have to occur at brand-owned touchpoints (Lemon \& Verhoef, 2016) in order to allow interventions to be implemented. Of these tourist behaviours, those with the biggest detrimental effect become candidate behaviours for targeting. In the example provided in Figure 2, having the hotel room cleaned daily, even if it is not necessary, emerges as having substantial negative effects on the environment.

Once a single or a small set of target behaviours has been identified, the reasons which drive those particular behaviours need to be understood. Typically, understanding reasons for behaviour will require a qualitative investigation: observing tourists, talking to tourists, and talking to staff. For each reason revealed during this stage, an assessment is required about the likelihood of being able to remove entirely or reduce the driving force in terms of causing the target behaviour. In the example used in Figure 2, a range of reasons is identified which explain why tourists staying at a hotel have their room cleaned every day. Some of these reasons cannot be changed. For example, if tourists insist on having a sparkling clean room every day, it is unlikely that anything the hotel does will change that high-level expectation. Other reasons could potentially be targeted with a well-developed intervention. Tourists are often cynical about hotels requesting their help to save the environment, for example. They do not trust that such request are motivated by genuine environmental concern, assuming instead that the request is an attempt to save money. If this is the reason for hotel guests having their rooms cleaned daily, it may be possible to make them waive their room clean by openly stating the cost of a room clean, and then offering to share the savings with them, either by refunding money or by offering a voucher. 
In terms of behavioural theory, such an intervention would align well with equity theory (Adams, 1963; Adams \& Freedman, 1976), which postulates that people have a need to balance out the give and take in interpersonal relationships. When the hotel offers a voucher or a refund, the guest may feel that this warrants waiving a room clean they do not really need; it may establish what the hotel guest perceives as a reasonable level of equity.

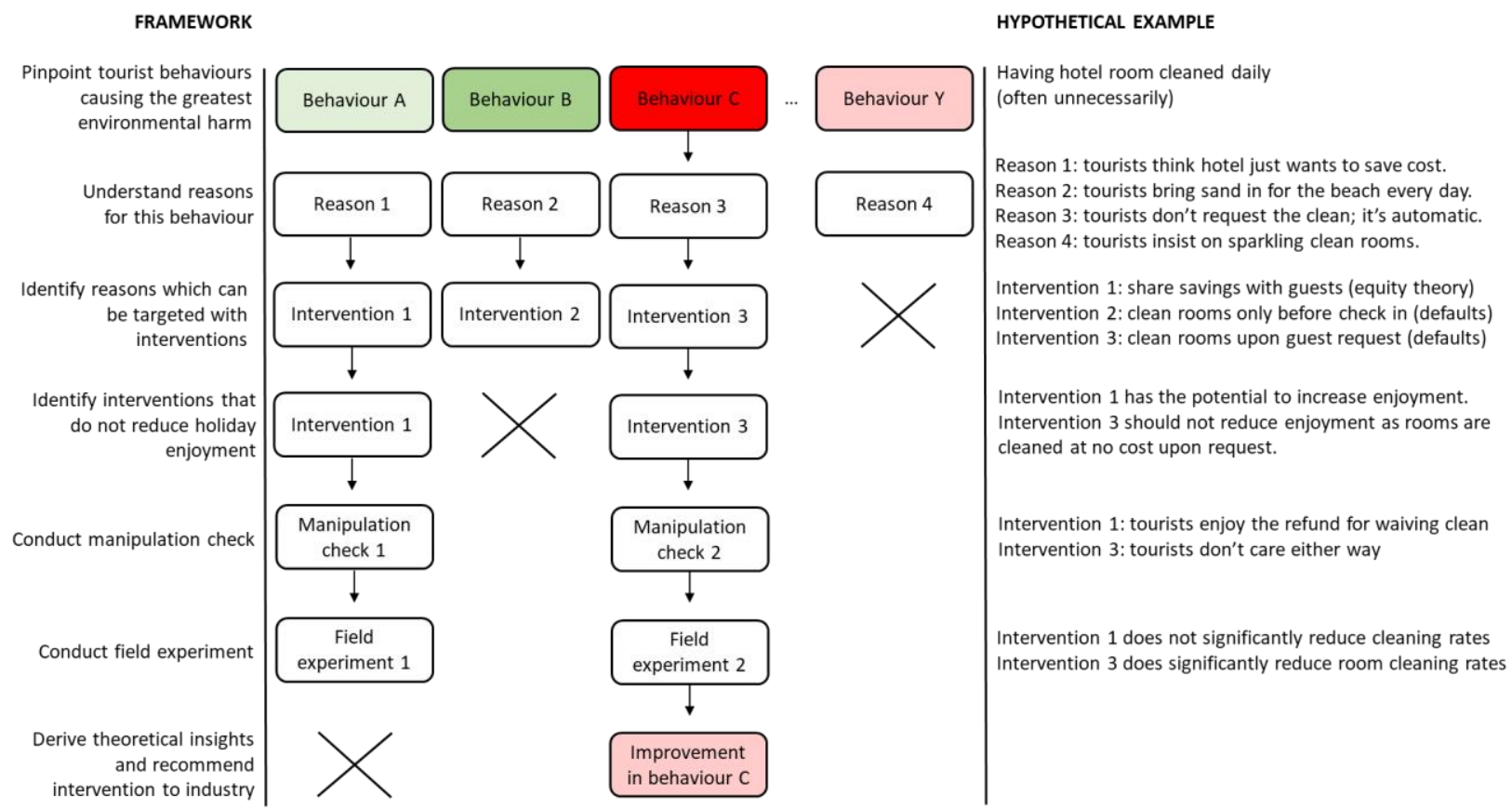

Fig. 2. A framework for designing and experimentally testing interventions aimed at reducing the environmental harm caused by tourists at the destination.

The refund or voucher serves as the intervention. The effectiveness of any intervention has to be empirically tested in a field experiment to ensure that the researcher is in control of the causeand-effect link to be tested, and to ensure that the intervention works in the real business context. But field experimentation is labour intensive, expensive and risky. It is important, therefore, to conduct a manipulation check before the field experiment. The purpose of a manipulation check is to make sure that the intervention has the intended effect (see Viglia \& Dolnicar (2020) for a detailed discussion of experimental research in tourism). The refund or voucher should reduce the scepticism hotel guests have about the hotel's motivation when asking them to waive room cleans; this intervention should instead create a sense of equity. Only if this is indeed achieved, there is reason to believe that the target behaviour will change as a result.

As opposed to the model proposed by Steg and Vlek (2009), in the tourism context, interventions are limited to those that do not cause the tourism businesses additional cost - which would reduce the likelihood of uptake - and those that do not increase effort or reduce pleasure for the tourists. The latter conditions align well with the requirement of operational excellence and value enhancement postulated by Dhebar (2013) in the context of designing compelling customer touchpoint architecture. 
Interventions can be eliminated throughout the process. Although this case is not illustrated in Figure 2, it is not uncommon for interventions to be eliminated when they fail the manipulation check. Those interventions that pass the manipulation check have to be put to the test in a field experiment using an empirical measure of the actual (not the stated intended) target behaviour as the dependent variable and, importantly, controlling for all possible intervening variables. The challenge of conducting field experimentation is that the real world is not as sterile as a laboratory. As a consequence, the researcher cannot control all the aspects of the exact situation in which the study is conducted. In the field, many external factors can affect the outcome of the experiment. These need to be controlled for, or accounted for in the data analysis. If a hotel is at the beach and bringing sand from the beach is a key reason for guests wanting the room cleaned daily, then a week of rain may significantly change the demand for room cleaning, as the guests engage in activities other than going to the beach. This could lead to erroneous conclusions. Identifying and controlling for potential intervening effects is therefore critically important when the effectiveness of the interventions is tested in the field.

Only if field experimentation proves interventions to be effective, can they be recommended for industry uptake. But proof of effectiveness in a field experiment is not only of practical value. It also serves as empirical evidence of cause-and-effect relationships. Experiments lead to third order knowledge or principles (Rossiter 2001; 2001): they permit firm conclusions about drivers of specific behaviours. As such, they contribute reliable and valid empirical knowledge which, in many instances, leads to theoretical insights and developments.

\section{Conclusions and practical implications}

The negative environmental consequences of tourism are well understood. It is now time to develop design approaches to reduce environmental harm to a minimum, while still permitting tourism industries around the world to flourish and support local communities, and tourists to enjoy their well-deserved holidays. This article discussed approaches that have already been proven to achieve this, including:

- providing tourists with information about how many of their fellow tourists have displayed a specific environmentally friendly behaviour (Goldstein, Cialdini \& Griskevicius, 2008);

- sharing savings resulting from the environmentally friendly behaviour with tourists (Dolnicar, Kneževič Cvelbar \& Grün, 2019a);

- providing real-time feedback on resource use or environmental damage caused (Tiefenbeck et al., 2019).

- introducing games which incentivise the desired environmentally friendly behaviour and, in so doing, increase holiday enjoyment (Dolnicar, Juvan \& Grün, 2020);

- getting tourists to commit to the desired behaviour and, optimally, provide them with a publicly visible symbol of their commitment (Baca-Motes, Brown, Gneezy, Keenan \& Nelson, 2012);

- $\quad$ reducing plate sizes to reduce plate waste (Kallbekken \& Sælen, 2013); 
- reducing embarrassment of returning to the buffet repeatedly using a table sign to reduce plate waste (Kallbekken \& Sælen, 2013);

- $\quad$ using videos to elicit specific emotions before booking decisions (Araña \& León, 2016);

- changing defaults by integrating carbon offsets in the regular price and offering customers to opt out, instead of opting in (Araña \& León, 2013), by offering daily room cleans upon request, rather than by default (Kneževič Cvelbar, Grün \& Dolnicar, 2020), or by offering guests recycled paper serviettes at the breakfast paper by default, and inviting them to get a thick cotton serviette from the buffet if they would like one (Dolnicar, Kneževič Cvelbar \& Grün, 2019b).

These approaches should be adopted by tourism businesses around the world as a matter of urgency. The article also offers suggestions about design options with the highest success, and a methodological framework to guide academic researchers and tourism industry in the systematic development of new design approaches.

To be able to proactively design for environmentally friendly tourism, it is necessary to first develop insight, a theory of the reasons for the occurrence of the environmentally unfriendly behaviour. An example of such a theory, derived from analytic qualitative research (Rossiter, 2011), is a model that postulates drivers of plate waste at hotel buffets (Dolnicar \& Juvan, 2019). As soon as such a theory is available, or at least individual insights about likely reasons for the undesirable behaviour that comes at high environmental cost, it is then possible to develop theory-based interventions aimed at modifying these behaviours. Typically such interventions will be informed by broader theories of human behaviour. These interventions have to occur at brand-owned touchpoints because the intervention itself has to be under the control of the tourism provider. As opposed to other context, in tourism, the design of the intervention has to occur within two critically important boundary conditions: no reduction in the quality of the vacation experience for the tourist, and no increase in cost for the business implementing the intervention.

All proposed interventions need to be empirical tested. Typically, this process will involve a manipulation check to demonstrate that the interventions works in the way it is theoretically intended to work, followed by an experimental study which tests whether the intervention has a significant effect on the dependent variable of interest. Only if that can be established in the field, can the intervention be broadly disseminated for uptake by tourism industry.

The present article focuses on designing tourism services in a more environmentally friendly way by using tourist behaviour as the starting point. Similarly, other groups could be targeted in future research. For example, staff represent an excellent target group given that they are paid by the businesses that wish to reduce environmental harm. While the same framework can be used for the identification, development and testing of interventions, it is likely that the success rate will be higher given the obligation of staff to comply with instructions of their employers. Another and critically important target group for future research are managers of tourism businesses. Even the most effective intervention is useless if it is not implemented in the business. Managers are the gatekeepers. Many of the interventions discussed in this article reduce operating cost, making it attractive to managers to adopt them. But will they? If not, why not? These are key questions that remain to be answered. 


\section{References}

Abadie, A. \& Gay, S. (2006). The impact of presumed consent legislation on cadaveric organ donation: a cross-country study. Journal of Health Economics, 25(4):599-620.

Adams, J. S. (1963). Toward an understanding of inequity. The Journal of Abnormal and Social Psychology, 67, $422-436$.

Adams, J. S., \& Freedman, S. (1976). Equity theory revisited: Comments and annotated bibliography. Advances in Experimental Social Psychology, 9, 43-90.

Ajzen, I. (1985). From intentions to actions: A theory of planned behavior. In: Kuhl \& Beckmann (Eds.), Action control (pp. 11-39). Springer, Berlin, Heidelberg.

Andreoni, J., \& Bernheim, B.D. (2009). Social Image and the 50-50 Norm: A Theoretical and Experimental Analysis of Audience Effects. Econometrica, 77 (5), 1607-36.

Araña, J. E. \& León, C. L. (2013). Can defaults save the climate? Evidence from a field experiment on carbon offsetting programs. Environmental and Resource Economics, 54(4):613-626.

Araña, J. E., \& León, C. J. (2016). Are tourists animal spirits? Evidence from a field experiment exploring the use of nonmarket based interventions advocating sustainable tourism. Journal of Sustainable Tourism, 24(3), 430-445.

Baca-Motes, K., Brown, A., Gneezy, A., Keenan, E. A., \& Nelson, L. D. (2012). Commitment and behaviour change: Evidence from the field. Journal of Consumer Research, 39(5), 1070-1084.

Becken, S. \& Dolnicar, S. (2016) Uptake of Resource Efficiency Measures by Small and Medium-Sized Accommodation and Food Service Providers. Journal of Hospitality and Tourism Management, 26: 45-49.

Bramwell, B., \& Lane, B. (1993). Sustainable tourism: An evolving global approach. Journal of Sustainable Tourism, $1(1), 1-5$.

Buckley, R. (2011). 20 answers: Reconciling air travel and climate change. Annals of Tourism Research, 38(3), 11781181.

Davidai, S., Gilovich, T., \& Ross, L. D. (2012). The meaning of default options for potential organ donors. Proceedings of the National Academy of Sciences, 109(38), 15201-15205.

Dellaert, B. G., Johnson, E. J., \& Baker, T. (2019). Choice Architecture for Healthier Insurance Choices: Ordering and Partitioning Can Improve Decisions. ERIM Report Series Reference.

Dhebar, A. (2013). Toward a compelling customer touchpoint architecture. Business Horizons, 56(2), 199-205.

Dolnicar, D., Kneževič Cvelbar, L., Grün, B. (2019a) A sharing-based approach to enticing tourists to behave more environmentally friendly. Journal of Travel Research, 58(2), 241-252.

Dolnicar, S. \& Juvan, E. (2019) Drivers of plate waste: A mini theory of action based on staff observations. Annals of Tourism Research, 78, 102731, https://doi.org/10.1016/j.annals.2019.05.008

Dolnicar, S., \& Grün, B. (2009). Environmentally friendly behaviour: Can heterogeneity among individuals and contexts/environments be harvested for improved sustainable management? Environment and Behavior, 41(5), 693714.

Dolnicar, S., Juvan, E. \& Grün, B. (2020) Reducing the plate waste of families at hotel buffets. Tourism Management.

Dolnicar, S., Kneževič Cvelbar, L. \& Grün, B. (2017) Do pro-environmental appeals trigger pro-environmental behavior in hotel guests? Journal of Travel Research, 56(8):988-977.

Dolnicar, S., Kneževič Cvelbar, L., Grün, B. (2019b) Changing service settings for the environment - how to reduce negative environmental impacts without sacrificing tourist satisfaction. Annals of Tourism Research, 76:301-304.

Everett, J. A., L. Caviola, G. Kahane, J. Savulescu \& Faber, N. S. (2015). Doing good by doing nothing? The role of social norms in explaining default effects in altruistic contexts. European Journal of Social Psychology, 45(2):230-241.

Festinger, L. (1962). A theory of cognitive dissonance (Vol. 2). Stanford University Press.

Food and Agriculture Organization of the United Nations (2013) Food wastage footprint - Impacts on natural resources: Summary report, http://www.fao.org/3/i3347e/i3347e.pdf, last accessed 20.6.2019.

Goldstein, N. J., Cialdini, R. B., \& Griskevicius, V. (2008). A room with a viewpoint: Using social norms to motivate environmental conservation in hotels. Journal of Consumer Research, 35(3), 472-482.

Gössling, S. (2005). Tourism's contribution to global environmental change: space, energy, disease and water. In Hall \& Higham (eds), Tourism recreation and climate change: International perspectives. Clevedon: Channel View Publications, 286-300.

Heider, F. (1958) The psychology of interpersonal relations. Hoboken: John Wiley \& Sons.

Johnson, E. J. \& Goldstein, D. G. (2004). Defaults and donation decisions. Transplantation, 78(12):1713-1716.

Johnson, E. J. and D. G. Goldstein. 2004. "Defaults and donation decisions.” Transplantation 78(12):1713-1716.

Johnson, E. J., J. Hershey, J. Meszaros \& Kunreuther, H. (1993). Framing, probability distortions, and insurance decisions. Journal of Risk and Uncertainty, 7(1):35-51.

Johnson, E. J., Shu, S. B., Dellaert, B. G., Fox, C., Goldstein, D. G., Häubl, G., Larrick, R. P., Payne, J. W., Peters, E., Schkade, D., Wansink, B. \& Weber, E.. (2012). Beyond nudges: Tools of a choice architecture. Marketing Letters, 23(2), 487-504.

Juvan, E., \& Dolnicar, S. (2014). The attitude-behaviour gap in sustainable tourism. Annals of Tourism Research, 48, 7695. 
Juvan, E., Grün, B. \& Dolnicar, S. (2018) Biting off more than they can chew: food waste at hotel breakfast buffets. Journal of Travel Research, 57(2), $232-242$.

Kahneman (1999) Objective happiness. In: Kahneman (ed), Well-being: The foundations of hedonic psychology. New York: Russell Sage.

Kallbekken \& Sælen (2013) Nudging' hotel guests to reduce food waste as a win-win environmental measure. Economics Letters, 119(3), 325-327.

Kneževič Cvelbar, L., Grün, B. \& Dolnicar, S. (2020) To clean or not to clean?” Reducing daily routine hotel room cleaning by letting tourists answer this question for themselves. Journal of Travel Research.

Krippendorf, J., Zimmer, P., \& Glauber, H. (1988). Für einen anderen Tourismus. Probleme-Perspektiven—Ratschläge, Frankfurt/M.

Lemon, K. N., \& Verhoef, P. C. (2016). Understanding customer experience throughout the customer journey. Journal of Marketing, 80(6), 69-96.

Lenzen, M., Sun, Y. Y., Faturay, F., Ting, Y. P., Geschke, A., \& Malik, A. (2018). The carbon footprint of global tourism. Nature Climate Change, 8(6), 522.

Leonard, T. C. (2008). Richard H. Thaler, Cass R. Sunstein, Nudge: Improving decisions about health, wealth, and happiness. Constitutional Political Economy, 19(4): 356-360.

Locke, E. A., \& Latham, G. P. (2002). Building a practically useful theory of goal setting and task motivation: A 35-year odyssey. American Psychologist, 57(9), 705-717.

Mair, J., \& Bergin-Seers, S. (2010). The effect of interventions on the environmental behaviour of Australian motel guests. Tourism and Hospitality Research, 10(4), 255-268.

Midden, C., Kaiser, F., \& McCalley, T. (2007). Technology's four roles in understanding individuals' conservation of natural resources. Journal of Social Issues, 63(1), 155-174.

Rossiter, J. R. (2002) The five forms of transmissible, usable marketing knowledge. Marketing Theory, 2(4), 369-380.

Rossiter, J.R. (2001) What is marketing knowledge? Stage I: forms of marketing knowledge. Marketing Theory, 1(1), 926.

Rossiter, J.R. (2011). Measurement for the Social Sciences. The C-OAR-SE Method and Why it Must Replace Psychometrics. New York: Springer.

Samuelson, W. \& Zeckhauser, R. (1988). Status quo bias in decision making. Journal of Risk and Uncertainty, 1(1):7-59.

Schwartz, S. H. (1977) Normative influences on altruism. In: Advances in experimental social psychology (Vol. 10, pp. 221-279). Academic Press.

Steg , L. \& Vlek, C . (2009) Encouraging pro-environmental behaviour: An integrative review and research agenda. Journal of Environmental Psychology, 29: 309-317.

Stern, P. (2000). Toward a Coherent Theory of Environmentally Significant Behavior. Journal of Social Issues, 56(3), 407-424.

Sunstein, C. \& Thaler, R. (2008). Nudge. The politics of libertarian paternalism. New Haven.

Tajfel, H. (1979) Individuals and groups in social psychology. British Journal of Social and Clinical Psychology, 18(2), 183-190.

Tiefenbeck, V., Wörner, A., Schöb, S., Fleisch, E., \& Staake, T. (2019). Real-time feedback promotes energy conservation in the absence of volunteer selection bias and monetary incentives. Nature Energy, 4(1), 35-41.

The Authors (in press) A review of experimental research in tourism. Annals of Tourism Research.

The World Bank (2019) International tourism, number of arrivals, https://data.worldbank.org/indicator/ST.INT.ARVL, last accessed 20.6.2019.

United National World Tourism Organisation (2016) UNWTO tourism highlights. Madrid: United National World Tourism Organisation.

United Nations Environment Programme and World Tourism Organization. (2012). Tourism in the green economybackground report. Madrid: United National World Tourism Organisation.

Viglia, G. \& Dolnicar, S. (2020) A review of experiments in tourism and hospitality. Annals of Tourism Research, 80, 102858 . 